\title{
PENERAPAN METODE HTB DAN DIFFSERV GUNA PENINGKATAN QOS PADA LAYANAN VIDEO STREAMING
}

\author{
Mitra Unik ${ }^{1}$, Soni ${ }^{2}$, Randra Aguslan Pratama ${ }^{3}$ \\ ${ }^{123}$ Fakultas Ilmu Komputer, Universitas Muhammdiyah Riau \\ email: $\underline{1}$ mitraunik@umri.ac.id, ${ }^{2}$ soni@umri.ac.id, ${ }^{3}$ randra@ student.umri.ac.id
}

\begin{abstract}
One of the popular internet services in use today is video streaming, either live (live streaming) or pre-recorder. Streaming video is a type of streaming media where data from video files is continuously transmitted over the internet to remote users. This fundamental problem appears to be influenced by the biggest factor which is the limited infrastructure of network resources which causes poor video quality. The process of digital video communication is known to consume quite a large resource, because in general the bandwidth requirements for sending Video and Audio signals. To maintain the quality of the video being played, there are several instruments needed, one of which is a data connection that is required to have Quality of Service (QoS). The parameters used in the measurement of QoS are delay, jitter, packet loss, throughput. This study uses the PPDIO method as a workflow with a Network Lifecycle approach. In this research, there are many factors that influence the quality of video, namely network factors and hardware factors. The test results obtained are not absolute, so it is possible that there will be differences in subsequent testing. Encoding also affects the quality of the video. Bandwidth equalization according to priority when the traffic conditions of all packets are full. Based on a comparative analysis of QoS parameter calculations using HTB and Diffserv methods, a comparison of throughput, jitter and delay does not differ greatly between clients.
\end{abstract}

Keywords: Video Streaming, Diffserv, HTB, QoS

\begin{abstract}
Abstrak
Salah satu layanan dari internet yang populer digunakan saat ini adalah video streaming, baik secara langsung (live streaming) atau pre-recorder. Streaming video merupakan jenis streaming media dimana data dari file video secara terus menerus dikirimkan melalui jaringan internet ke pengguna jarak jauh. Permasalahan mendasar ini muncul dipengaruhi oleh faktor terbesar yaitu terbatasnya infrastruktur sumber daya jaringan yang menyebabkan kualitas video yang buruk. Proses komunikasi digital video, diketahui menghabiskan resource yang cukup besar, dikarenakan Secara umum kebutuhan bandwidth untuk mengirimkan sinyal Video dan Audio. Guna menjaga kualitas dari video yang dimainkan, terdapat beberapa instrument yang dibutuhkan, salah satunya adalah koneksi data yang wajib memiliki Quality of Service $(Q o S)$. Adapun Parameter yang digunakan dalam pengukuran QoS adalah delay, jitter, packet loss, Throughput. Penelitian ini menggunakan metode PPDIO sebagai alur kerja dengan pendekatan Network Lifecycle. Pada penelitian ini didapat Banyak faktor yang mempengaruhi kualitas dari video yaitu faktor jaringan dan faktor dari Hardware. Hasil pengujian didapat tidaklah mutlak sehingga tidak menutup kemungkinan akan ada perbedaan pada pengujian selanjutnya. Encoding juga mempengaruhi kualitas dari video. pemerataan Bandwidth sesuai prioritasnya saat kondisi traffic seluruh paket penuh. Berdasarkan analisa perbandingan perhitungan parameter QoS menggunakan metode HTB dan Diffserv, didapatkan perbandingan troughput, jitter dan delay yang tidak berbeda jauh antara klien.
\end{abstract}

Kata kunci: Video streaming, Diffserv, HTB, QoS

\section{PENDAHULUAN}

Pertumbuhan akan opsi video on Deman (VOD) yaitu dimana pemirsa dapat mengunduh atau striming konten siaran TV baik secara langsung (live) atau pun tunda (prerecord), membuat pemirsa memiliki kontrol penuh terkait siaran yang akan ditonton. Video
Striming telah menjadi populer di seluruh dunia sebagai cara yang menjanjikan untuk memberikan layanan terkait Striming TV maupun Video [1]. Survei Online tahun 2015 Nielsen di 61 negara mengatakan mereka menonton siaran TV dengan cara Striming [2]. Striming adalah salah satu bentuk teknologi yang memperkenankan berkas digunakan 
secara langsung tanpa menunggu selesainya pengunduhan data (download) dan berlangsung secara kontinyu tanpa interupsi [3]. Video merupakan tayangan gambar bergerak disertai dengan suara yang awalnya diolah dan ditransmisikan dalam bentuk analog. Selanjutnya, dengan munculnya digital circuit dan berkembangnya komputer telah mengubah video analog menjadi video digital dengan berbagai jenis format video [4].

Aplikasi-aplikasi striming video pada jaringan memerlukan suatu persyaratan Quality of Service (QoS) tertentu agar selama proses mentransmisikan tidak terlalu banyak paket yang hilang. Sementara itu, QoS dapat dikatakan sebagai suatu terminologi yang digunakan untuk mendefinisikan karakteristik suatu layanan (service) jaringan untuk mengetahui seberapa baik kualitas yang ada pada layanan tersebut [3]. Quality of Service (Qos) adalah kemampuan suatu jaringan untuk membersihkan layanan yang lebih baik pada trafik data tertentu pada berbagi jenis platform teknologi. Masalah utama dari video streaming adalah Delay, Jitter, Packet loss, dan Throughput [5]. QoS didesain untuk membantu pengguna (end user) menjadi lebih produktif dengan memastikan bahwa user mendapatkan kinerja yang handal dari aplikasi - aplikasi berbasis jaringan.

Proses komunikasi digital video, diketahui menghabiskan sumberdaya yang cukup besar, dikarenakan secara umum ada dua (2) kebutuhan bandwidth yang perlu dipenuhi, yaitu:

1. Kebutuhan bandwidth untuk mengirimkan sinyal gambar / video

2. Kebutuhan bandwidth untuk mengirimkan sinyal audio / suara.

Aplikasi striming video membutuhkan bitrate cukup tinggi, sehingga proses capturing dan live decoding pada sisi server serta faktor pengelolaan bandwidth menjadi faktor utama dalam menjaga kualitas video [3].

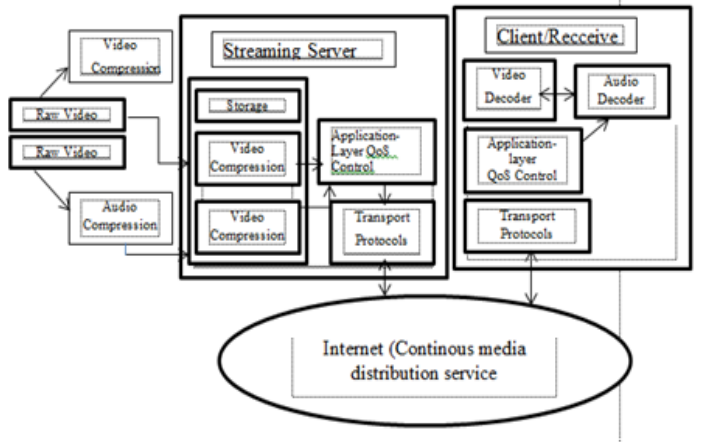

Gambar 1. Arsitektur umum Video Streaming

Permasalahan yang kerap muncul pada striming video adalah gangguan seperti video menjadi "patah-patah / tertunda" yang disebut Delay, jeda waktu antara frame / frame video yang lama (latency) dan juga jitter dan package lost yang juga turut mempengaruhi penurunan performa kualitas video yang disajikan kepada penonton (Klien) [6].

Hierarchical Token Bucket (HTB) dan Differentiated services (Diffserv) adalah metode yang dikenal mampu untuk menjaga kualitas dari layanan pada jaringan komputer walaupun dengan pendekatan yang berbeda. HTB menerapkan disiplin antrian yang menerapkan link sharing secara presisi dan adil [7]. Dalam konsep link sharing jika suatu kelas meminta kurang dari jumlah service yang telah ditetapkan untuknya maka sisa bandwidth akan didistribusikan ke kelas-kelas lain yang meminta service.

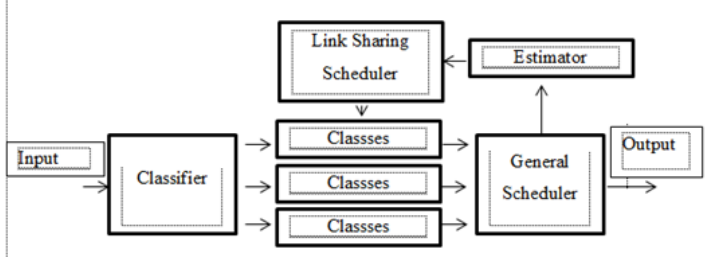

Gambar 1. Alur kerja Hireriarchichal Token Bucket

Diffserv adalah arsitektur jaringan komputer yang menentukan mekanisme sederhana dan scalable untuk mengklasifikasikan dan mengelola lalu lintas jaringan dan menyediakan kualitas layanan (QoS) pada jaringan IP modern. metode Diffserv menggunakan nilai Differentiated Service Code Point (DSCP) untuk mengklasifikasikan pengiriman paket ke dalam kelas-kelas sehingga paket dikirim sesuai dengan prioritas yang telah ditentukan. Selanjutnya Diffserv juga merupakan skema implementasi QoS yang menyediakan layanan yang berbeda dengan membagi trafik dan memperlakukan setiap kelas secara berbeda. Identifikasi kelas dilakukan dengan memasang sebuah kode yg disebut Differentiated Service Code Point (DSCP), kedalam paket IP. Ini dilakukan tidak dengan header baru, tetapi dengan mengantikkan field TOS (type of service) di header IP dan DS filed [8].

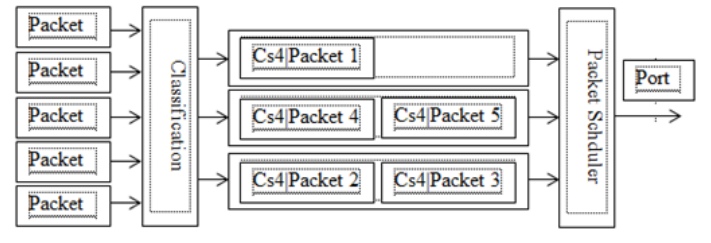


Gambar 2. Alur kerja Diffserv

Adapun Penelitian ini berfokus pada bagaimana menerapkan HTB dan Diffserv sebagai metode untuk melakukan manajemen bandwidth lalu menganalisis serta melakukan pengujian performansi serta men komparasi metode Diffserv dan HTB untuk mengetahui nilai Quality of Service (QoS) sehingga didapatkan metode yang paling cocok untuk video streaming guna sebagai dasar untuk mengoptimalkan performa layanan video streaming.

Identifikasi masalah yang timbul, yaitu pengoptimalan bandwidth pada beberapa klien yang terkoneksi pada satu jaringan video striming dimana kerap muncul pada gangguan seperti video menjadi "patah-patah / tertunda" (Delay), jeda waktu antara frame/frame video yang lama (latency).

\section{METODE PENELITIAN}

Metode / Tahapan yang digunakan untuk menghasilkan suatu pengetahuan baru adalah menggunakan metode PPDIOO (Prepare and Plan, Design, Implementation, Operate and Optimize) [9]. PPDIOO merupakan metode desain jaringan dengan pendekatan network lifecycle.

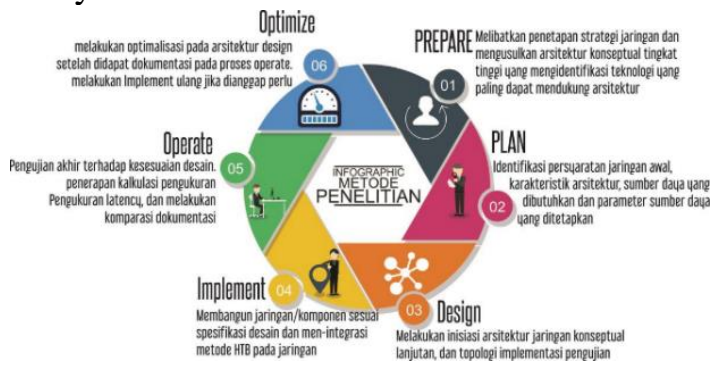

Gambar 3. Metode Perancangan Jaringan PPDIOO

Konsep mekanisme pengukuran Quality of Service (QoS) pada Video Striming dengan menggunakan jaringan Wireless dalam lingkungan jaringan area lokal (LAN) sederhana. Konsep QoS yang penulis gunakan adalah dengan membagi satu jaringan utama menjadi beberapa kelas yang memiliki layanan jaringan yang berbeda, hal ini dimaksudkan untuk memberikan layanan kepada user dengan tingkat prioritas dan kebutuhan akan layanan yang berbeda sehingga setiap user mendapatkan layanan sesuai dengan kebutuhan dan prioritas serta penggunaan sumber daya jaringan dapat lebih optimal.

Pada penelitian ini akan dilakukan 3 skenario, hasil dari pengamatan proses berjalannya skenario penelitian akan dijadikan tolak ukur analisa mekanisme penerapan metode HTB (Hierarchichal Token Bucket) dan Differentiated Service pada layanan Video Streaming

1. Skenario Penelitian

a. Skenario 1 pengujian dilakukan pada proses transmisi data antara Server dan Klien tidak menggunakan management bandwidth tanpa menggunakan metode HTB dan Diffserv dan pada klien yang terkoneksi pada server, melakukan streaming video diakses oleh tiga klien menggunakan notebook dan melakukannya secara bersamaan. Akan dilakukan pengukuran parameter QoS

b. Skenario 2 pengujian dilakukan pada proses transmisi data antara Server dan Klien menggunakan management bandwidth yang ada pada router dengan bandwidth yang telah ditentukan tanpa dapat memakai bandwidth yang sedang tidak digunakan dan pada klien yang terkoneksi pada server, melakukan streaming video diakses oleh tiga klien menggunakan notebook dan melakukannya secara bersamaan. Akan dilakukan pengukuran parameter QOS ( quality of services ).

c. Skenario 3 pengujian dilakukan pada proses transmisi data antara Server dan Klien menggunakan management bandwidth dan menggunakan metode HTB dan Diffserv dengan bandwidth yang telah ditentukan dan dapat mengoptimalkan bandwidth yang sedang tidak digunakan, pada klien yang terkoneksi pada server, melakukan streaming video diakses oleh tiga klien menggunakan notebook dan melakukannya secara bersamaan. Akan dilakukan pengukuran parameter QOS ( quality of services ).

2. Design Topologi

Topologi jaringan yang akan dirancang dimana Server Streaming terhubung ke Mikrotik dengan mode bridge yang nantinya sebagai penghubung antara klien dengan Server Streaming. Topologi ini yang nantinya digunakan untuk mengukur kinerja Quality of Service. 


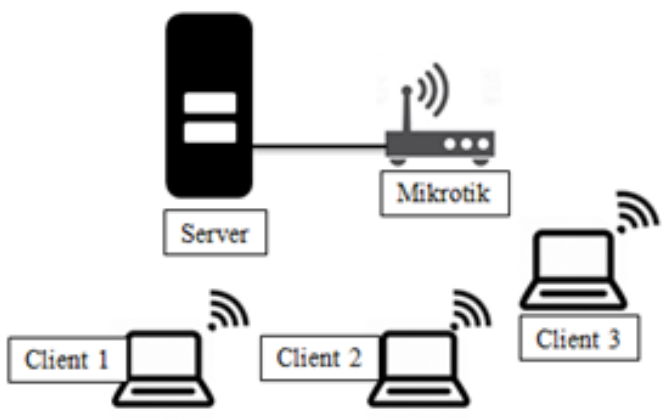

Gambar 4. Jaringan Topologi Lokal

Berdasarkan desain topologi yang telah didesain di atas, maka dapat dilihat bahwa terdapat ada 1 router yang saling terkoneksi di dalam 1 arsitektur jaringan, dimana ketiga Klien terhubung ke server melalui router. Pengujian dilakukan pada antar host yang terhubung pada tiap arsitektur jaringan dan membandingkan ketiga kualitas QoS pada tiap Klien pada masing-masing arsitektur jaringan.

\section{HASIL DAN PEMBAHASAN}

\section{Analisa QOS}

Responden dipilih dari Fakultas Ilmu Komputer Prodi Teknik Informatika Universitas Muhammadiyah Riau. Saat ini jumlah populasi mahasiswa prodi teknik

\subsection{Analisis Skenario}

Skenario ini berjalan pada jaringan Wi-Fi yang sudah memiliki jalur antara klien dan server, pengujian dilakukan pada 3 skenario berbeda.

- Skenario 1. Proses streaming video antara klien 10.10.10.251 yang terkoneksi pada server 192.168.1.6 yang terkoneksi pada router.

- Skenario 2. Proses streaming video antara klien 10.10.10.253 yang terkoneksi pada server 192.168.1.6 yang terkoneksi pada router

- Skenario 3. streaming video antara klien 10.10.10.254 yang terkoneksi pada server 192.168.1.6 yang terkoneksi pada router

Skenario akan menguji sebanyak 3 kali percobaan, dengan keterangan file tersebut:

Nama File yang akan diuji : The.Conjuring.2.2016.480p.BluRay_reupfilem-ane.mp4, Ukuran: $504 \mathrm{MB}$, Ekstensi: .MP4

Masing skenario akan mengukur beberapa variabel yaitu Throughput, Delay, Packet Loss, Jitter

penerapan (3 Klien dan 2 Klien). Perhitungan nilai dihitung dari tabel hasil delay di masing-
1.2 Data analisis perbandingan parameter QoS

Setelah melakukan pengujian pada 3 skenario penelitian, didapatkan hasil berupa perhitungan parameter QOS yang akan dijadikan bahan analisa perbandingan, analisa ini nantinya akan menghasilkan kesimpulan analisa kinerja mekanisme video streaming. Berikut adalah perbandingan perhitungan parameter QOS:

a. Throughput

Terdapat 3 buah skenario pengujian yang telah dilakukan guna melakukan analisa Throughput pada penelitian ini, selanjutnya didapat hasil rata-rata, sebagai berikut:

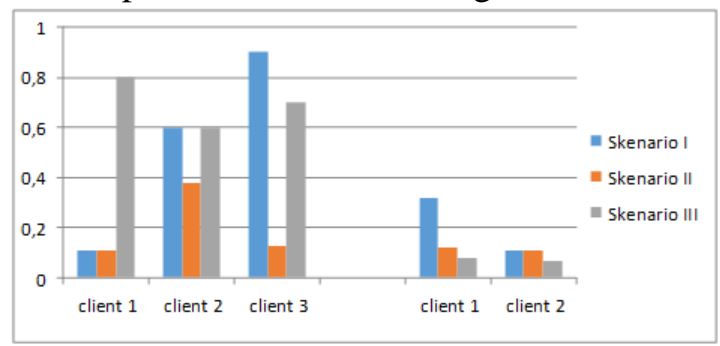

Gambar 3. Grafik Analisa perbandingan Throughput

Berdasarkan dari daftar gambar 3 didapatkan hasil skor rata-rata angka yang diperoleh dari Klien I, Klien II dan Klien III pada percobaan penerapan (3 Klien dan 2 Klien). Perhitungan nilai dihitung dari tabel hasil Throughput di masing-masing Klien, angka yang di dapat seperti Klien 1 yang berada di angka (0.1) Klien 2 yang berada di angka (0.6) dan Klien 3 yang berada di angka (0.9) dihitung dari nilai ratarata pada percobaan skenario I, II, dan III.

\section{b. Delay}

Terdapat 3 buah skenario pengujian yang telah dilakukan guna melakukan analisa Delay pada penelitian ini, selanjutnya didapat hasil rata-rata, sebagai berikut:

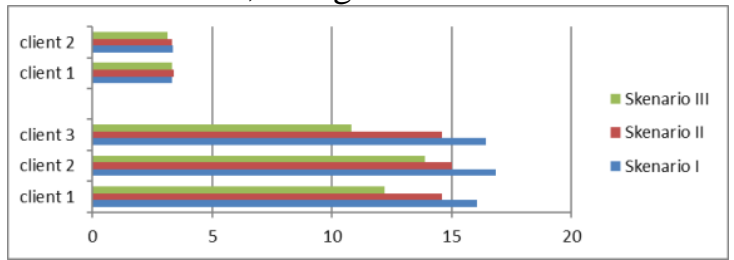

Gambar 4. Grafik Analisa Perbandingan Delay

Berdasarkan dari daftar gambar 4 didapatkan hasil skor rata-rata angka yang diperoleh dari Klien I, Klien II dan Klien III pada percobaan

masing Klien, angka yang di dapat seperti Klien 1 yang berada di angka (16) Klien 2 yang 
berada di angka (17..02) dan Klien 3 yang berada di angka (16.01) dihitung dari nilai ratarata pada percobaan skenario I, II, dan III.

c. Packet Loss

Terdapat 3 buah skenario pengujian yang telah dilakukan guna melakukan analisa packet Loss pada penelitian ini, selanjutnya didapat hasil rata-rata, sebagai berikut:

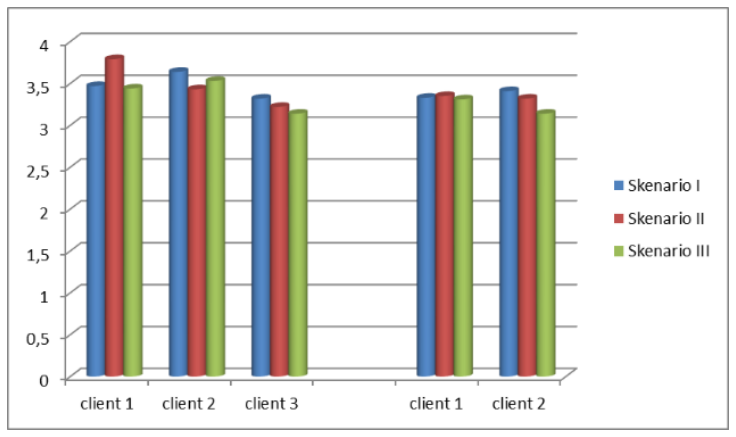

Gambar 5. Grafik Analisa Perbandingan Packet Loss

Berdasarkan dari daftar gambar 5 didapatkan hasil skor rata-rata angka yang diperoleh dari Klien I, Klien II dan Klien III pada percobaan penerapan ( 3 Klien dan 2 Klien). Perhitungan nilai dihitung dari tabel hasil paket loss di masing-masing Klien, angka yang di dapat seperti Klien 1 yang berada di angka (3.50) Klien 2 yang berada di angka (3.61) dan Klien 3 yang berada di angka (3.38) dihitung dari nilai rata-rata pada percobaan skenario I, II, dan III.

\section{d. Jitter}

Terdapat 3 buah skenario pengujian yang telah dilakukan guna melakukan analisa Jitter pada penelitian ini. Berdasarkan dari daftar gambar 6 didapatkan hasil skor rata-rata angka yang diperoleh dari Klien I, Klien II dan Klien III pada percobaan penerapan (3 Klien dan 2 Klien). Perhitungan nilai dihitung dari tabel hasil jitter di masing-masing Klien, angka yang di dapat seperti Klien 1 yang berada di angka (0.01) Klien 2 yang berada di angka (0.01) dan Klien 3 yang berada di angka (0.01) dihitung dari nilai rata-rata pada percobaan skenario I, II, dan III

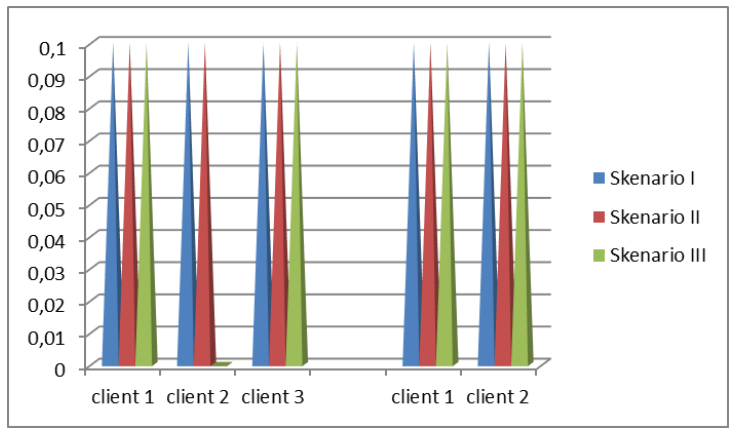

Gambar 6. Grafik Analisa Perbandingan Jitter

\subsection{Hasil perbandingan pada pengujian nilai QoS}

Masing-masing perhitungan dilakukan pada setiap penerapan skenario yang ada. Pengujian dilakukan dengan dan tanpa HTB. Bandwidth yang didapat tiap klien merata, sehingga Packet loss dan Delay tiap klien nilainya lebih kecil dan stabil dibandingkan tanpa penerapan HTB selanjutnya aktifitas antar klien tidak mempengaruhi klien lainnya. Berikut Hasil perbandingan menyeluruh nilai QoS

Tabel 1. Tabel Hasil perbandingan nilai QoS

\begin{tabular}{|c|c|c|c|c|}
\hline \multirow{2}{*}{$\begin{array}{c}\text { Penerapan } \\
\text { klien pada } \\
3 \text { Jenis } \\
\text { skenario }\end{array}$} & \multicolumn{4}{|c|}{ Parameter Quality of Service (QoS) } \\
\hline & Throughput & Delay & Packet Loss & Jitter \\
\hline 3 Klien & $\begin{array}{l}\text { Tanpa penerapan } \\
\text { Manajemen } \\
\text { Bandwidth (MB) } \\
\text { selisih antar klien } \\
\text { mencapai } 30 \% \text {, } \\
\text { sementara dengan } \\
\text { penerapan MB hanya } \\
15 \%\end{array}$ & $\begin{array}{l}\text { Selisih delay dengan Penerapan MB } \\
\text { tanpa HTB dan Diffserv serta } \\
\text { penerapan tanpa MB relatif sama, } \\
\text { namun setelah penerapan HTB dan } \\
\text { Diffserv memiliki selisih antar } \\
\text { klien. }\end{array}$ & $\begin{array}{l}\text { Selisih Packet Loss } \\
\text { dengan Penerapan MB } \\
\text { tanpa HTB dan Diffserv } \\
\text { serta penerapan tanpa MB } \\
\text { relatif sama, namun } \\
\text { setelah penerapan selisih } \\
\text { packet loss lebih sedikit. }\end{array}$ & $\begin{array}{l}\text { parameter jitter } \\
\text { ketiga client } \\
\text { tidak memiliki } \\
\text { selisih yang } \\
\text { banyak pada } \\
\text { tiap skenario. }\end{array}$ \\
\hline 2 Klien & $\begin{array}{l}\text { Tanpa penerapan MB } \\
\text { mencapai } 35 \% \text {. } \\
\text { Sedangkan setelah } \\
\text { dilakukan MB } \\
\text { perbandingan antar } \\
\text { klien tidak berubah } \\
\text { signifikan }\end{array}$ & $\begin{array}{l}\text { selisih delay antar klien pada tiap } \\
\text { jaringan hampir sama baik sebelum } \\
\text { jaringan di lakukan manajemen } \\
\text { bandwidth maupun setelah di } \\
\text { lakukan manajemen bandwidth }\end{array}$ & $\begin{array}{l}\text { Pada percobaan ini selisih } \\
\text { antar client pada } \\
\text { parameter packet loss } \\
\text { tidak begitu jauh baik } \\
\text { setelah penerapan HTB } \\
\text { dan Diffserv maupun } \\
\text { sebelum penerapan. }\end{array}$ & $\begin{array}{l}\text { parameter jitter } \\
\text { ketiga client } \\
\text { tidak memiliki } \\
\text { selisih yang } \\
\text { banyak pada } \\
\text { tiap skenario. }\end{array}$ \\
\hline
\end{tabular}




\section{SIMPULAN DAN SARAN}

Berdasarkan hasil penelitian yang telah dirangkum dalam beberapa analisa, peneliti dapat menyimpulkan hasil penelitian yaitu :

a. Untuk mendapatkan hasil yang bagus pada video, packet loss harus berkisar antara $0 \%$ - 3\%. Jika packet loss lebih dari 3\% hasil video yang didapatkan tidak memuaskan karena video mengalami banyak kerusakan pada gambar dan suara.

b. Quality of Service (QoS) bukan membatasi tetapi lebih kepada menjaga kualitas Bandwidth, tanpa adanya Quality of Service dalam sebuah Jaringan mengakibatkan ketidaksinambungan Bandwidth yang diterima klien.

c. Hierarchical Token Bucket (HTB) dan Diffserv merupakan teknik QoS yang mampu memaksimalkan Bandwidth yang tidak terpakai, sehingga kualitas pelayanan menjadi lebih meningkat. Hasil yang dicapai yaitu Setiap paket memiliki Bandwidth minimal. Setiap paket dapat memperoleh Bandwidth lebih dari Bandwidth minimal tetapi tidak melebihi Bandwidth maksimal, sehingga dengan HTB dan Diffserv pengoptimalan bandwidth lebih maksimal, selama traffic pada parent nya tidak penuh.

Terjadi pemerataan Bandwidth sesuai prioritasnya saat kondisi traffic seluruh paket penuh. Berdasarkan analisa perbandingan perhitungan parameter QoS menggunakan metode HTB dan Diffserv, didapatkan perbandingan troughput, jitter dan delay yang tidak berbeda jauh antara klien.

\section{TERIMA KASIH}

Riset penulis sebagian dibiayai oleh Hibah Penelitian Dosen Pemula dengan kontrak No: 009/L10/AK.04/KONTRAK-

\section{PENELITIAN/2019.}

\section{DAFTAR PUSTAKA}

[1] S. M. Fati, 2018. "IPTV : Delivery TV Services over IP Networks," in IPTV Delivery Networks: Next Generation Architectures for Live and Video-onDemand Services, no. June, Wiley.

[2] The Nielsen Company, 2016. "Video on demand 'How worldwide viewing Habits are cHanging in tHe evolving media landscape," United States.

[3] S. Taksande, 2015. K. Joshi, V.
Chikaraddi, and S. Raksha, "Video Streaming Techniques and Issues," IJARCST, 3, no. 1, pp. 1-4.

[4] D. Austerberry, 2013. The Technology Of Video \& Audio Streaming, 2nd ed. Burlington, Massachusetts, USA: Focal Press.

[5] D. Austerberry, 2006. The Technology of Video and Audio Streaming - Second Edition.

[6] D. Wu, Y. T. Hou, W. Zhu, Y.-Q. Zhang, and J. M. Peha, 2001. "Streaming Video over the Internet: Approaches adn Directions," IEEE Trans. Circuits Syst. Video Technol., 11, no. 3, pp. 282-300.

[7] M. D. aka Devik, "Home HTB," 2002. [Online]. Available: http://luxik.cdi.cz/ devik/qos/htb/. [Accessed: 03-Sep-2018].

[8] M. Czermin and A. Riedl, "Videoconferencing Systems in Corporate Networks," pp. 1-10.

[9] S. Wilkins, "Cisco's PPDIOO Network Cycle," Cisco Press, 2011. [Online]. Available:http://www.ciscopress.com/a rticles/article.asp? $\mathrm{p}=1697888 \&$ seqNum =2. [Accessed: 10-Mar-2018].

[10] (Studi Pada Kantor Kepolisian Resort Kota Besar Makassar)," J. Supremasi, vol. XI Nomor 1, no. ISSN 1412-517X, 2016 